Supplement of Hydrol. Earth Syst. Sci., 25, 429-446, 2021

https://doi.org/10.5194/hess-25-429-2021-supplement

(c) Author(s) 2021. This work is distributed under

the Creative Commons Attribution 4.0 License.

(c) (i)

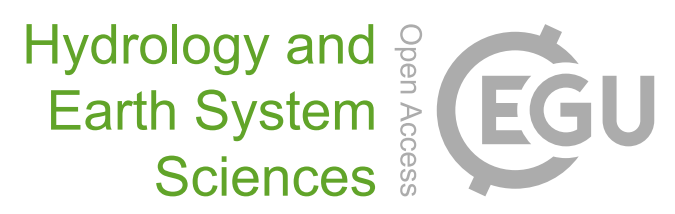

Supplement of

\title{
Progressive water deficits during multiyear droughts in basins with long hydrological memory in Chile
}

Camila Alvarez-Garreton et al.

Correspondence to: Camila Alvarez-Garreton (calvarezgarreton@gmail.com)

The copyright of individual parts of the supplement might differ from the CC BY 4.0 License. 


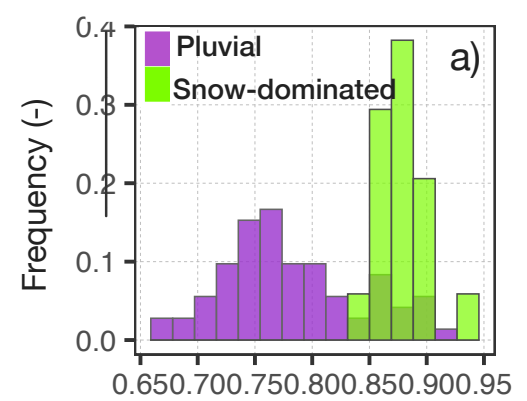

Pfw ratio

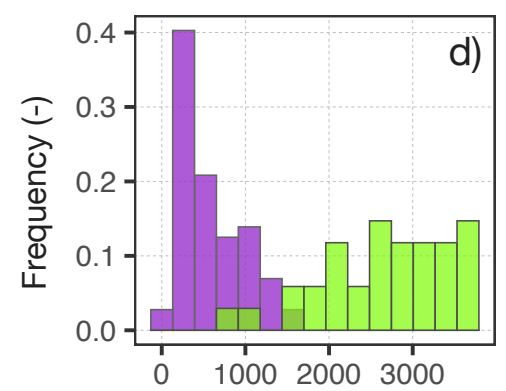

Median elevation ( $m$ a.s.I.)

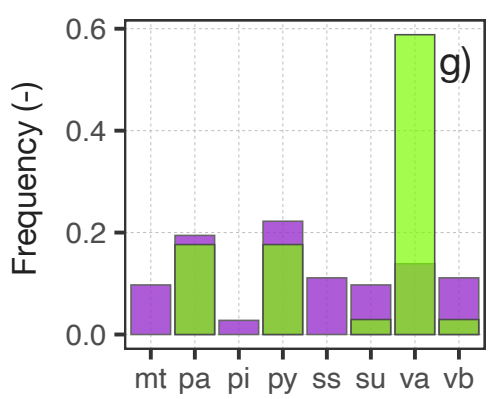

Main geologic class
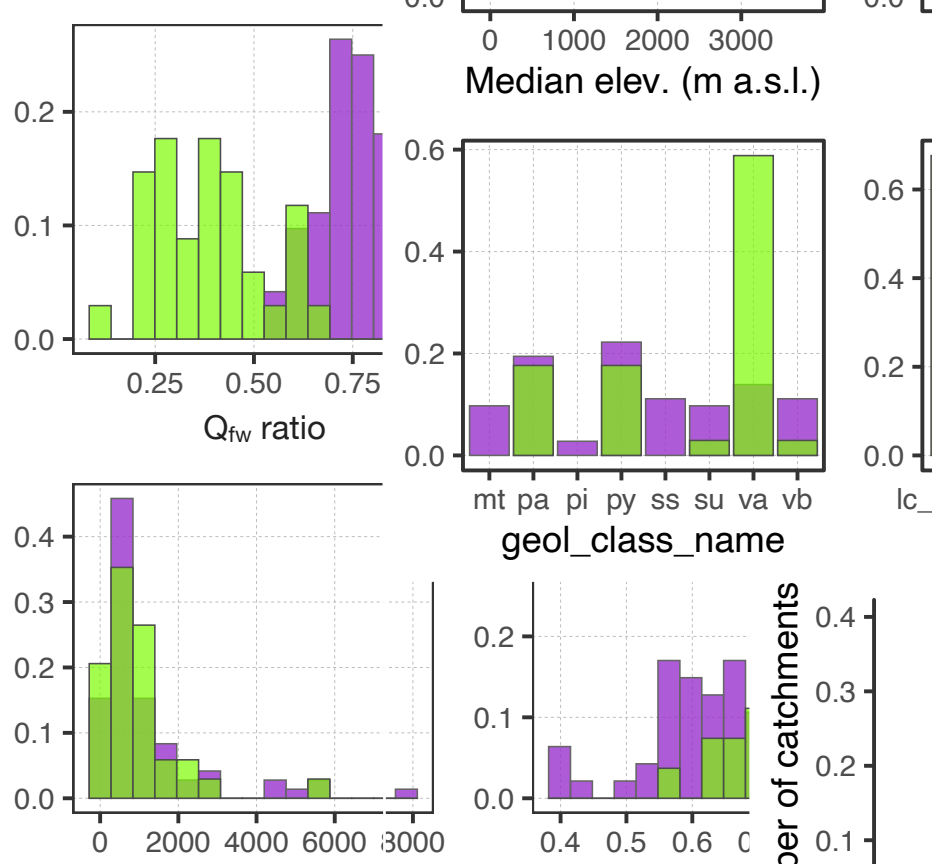

Area $\left(\mathrm{km}^{2}\right)$

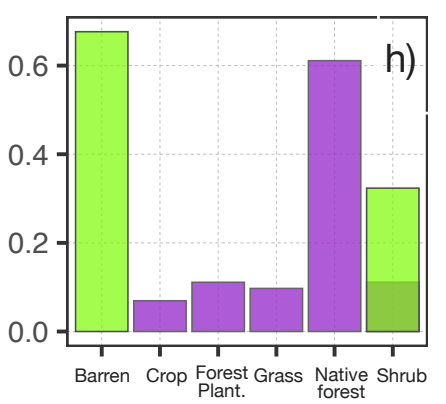

Main landcover class
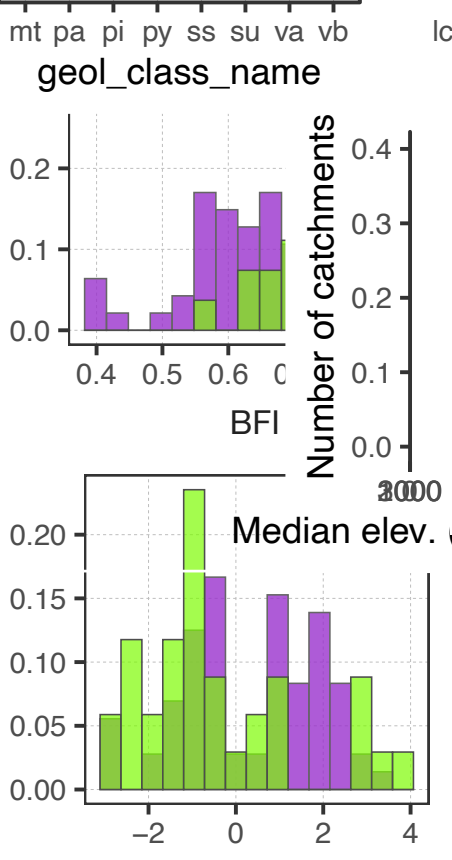

interv_degree

Figure S1: Main characteristics of snow-dominated and pluvial catchments, including $\mathbf{P}_{\mathrm{A}-\mathrm{S}}$ ratio (panel a), $\mathbf{Q}_{\mathrm{A}-\mathrm{S}}$ ratio (panel b), $\mathbf{S F}$ (panel c), mean elevation (panel d), area (panel e), baseflow index (panel f), main geologic class (panel g), main land cover class (panel h), and granted water used rights (panel i). 
a) Annual ET anomalies (\%)

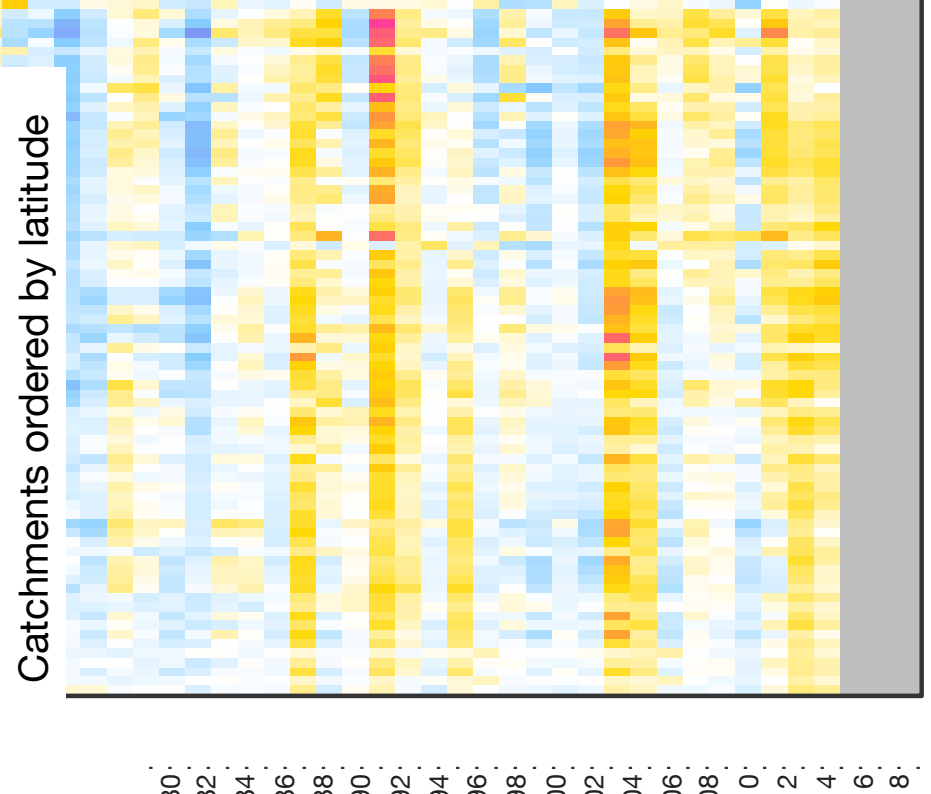

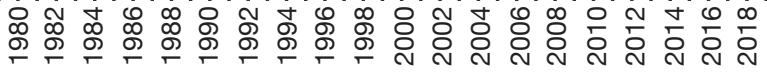

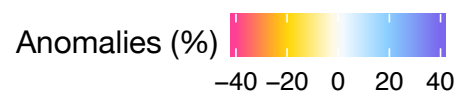

b) Annual ET z-score (-)

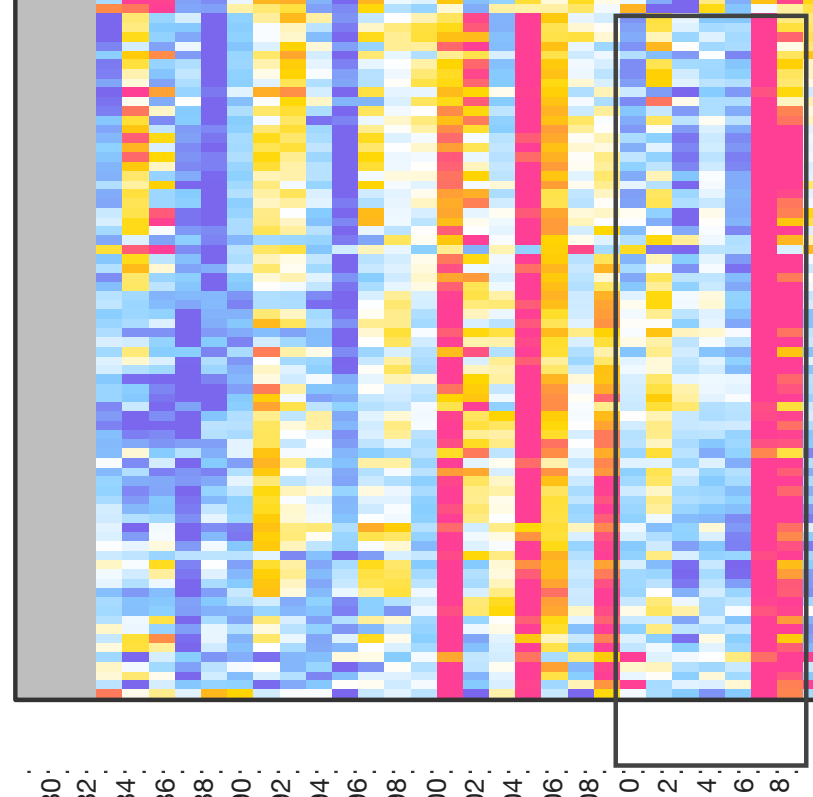

。

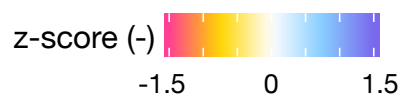

725 Figure S2: Panel b presents the z-score of simulated annual ET (computed as deviations from mean normalised by standard deviation). The MD period (April 2010 to March 2020) is highlighted in a grey box. Each row in the heatmaps corresponds to one study catchment and the catchments are sorted from north to south to illustrate regional patterns. 